while the Department determines the suitability of including this delivery system in the drug tariff.

Astra Pharmaceuticals Ltd,
St Albans, Herts AL1 3JW

Does low dietary intake of linoleic acid predispose to myocardial infarction?

SIR,-The paper by Dr H C R Simpson and others (11 September, p 683) reports interesting differences in blood fatty acid levels between men with recent myocardial infarction and controls. They emphasise their finding that the patients tended to have lower proportions of linoleic acid in the plasma triglycerides and in the red-cell membrane phosphatidyl choline, and they cite a report that the latter item reflects the type of fat eaten in recent weeks. They conclude: "These differences suggest that the type of dietary fat consumed might be an important factor in the genesis of ischaemic heart disease." That sentence simply repeats what most investigators in this field have been saying for years. The new element is the emphasis on linoleic acid.

All of us, including Dr Simpson and others, I am sure, would like to have better evidence on the actual diets eaten by the patients and controls than the inference from fatty acids in the red-cell membrane, but the data in their tables I and II merit comment. The table below summarises calculations that suggest neglect of palmitic acid by $\mathrm{Dr}$ Simpson and others. In the plasma triglycerides the proportion of linoleic acid is lower

population samples, however, the intra-individual variations tend to cancel out as random variables, and the averages for such groups are instructive.

In the Seven Countries study ${ }^{4}$ the population with the lowest incidence of coronary heart disease, the Japanese and the Greeks, had an average intake of only $3 \%$ of their dietary calories from linoleic acid, lower than the averages of 4 or $5 \%$ for men in Finland, in the Netherlands, and in the United States who had coronary death rates five to 10 times greater. The peculiarity of the diets of the Greeks and the Japanese was the low percentage of calories from saturated fatty acids : $8 \%$ for the Greeks and 3\% for the Japanese compared with the averages of $18-22 \%$ for the coronary-prone Americans, Dutch, and Finns.

In the Seven Countries study evaluation of the habitual diets of more than 12000 individual men was impossible with the resources available. Instead, the average diets of the men in the 16 cohorts were evaluated by means of repeated detailed seven-day surveys of statistical subsamples of the cohorts. We are confident that the death rates can be reliably related to the average compositions of the diets, but we cannot testify about individuals. In the Western Electric Company study in Chicago individual evaluation was possible on the basis of careful dietary surveys in two successive years of 1900 middle-aged men. ${ }^{7}$ In 19 years 242 of those Chicagoans were dead from coronary heart disease. Comparison of those men with the others showed a highly significant difference in the average diet scores calculated from the formulas in the references cited above. ${ }^{1-3}$ In those formulas the saturated fatty acids have much more weight than the polyenes.

Consideration of all these findings, as well as the data in the recent paper by Dr Simpson and others, indicates the need for much more study both in observational and in experimental epidemiology before conclusions can

\begin{tabular}{|c|c|c|c|c|}
\hline & $\begin{array}{l}\text { Patients } \\
(\mathrm{n}=32)\end{array}$ & $\begin{array}{l}\text { Controls } \\
(\mathrm{n}=32)\end{array}$ & Differences & $\mathrm{p}$ \\
\hline $\begin{array}{c}\text { Plasma triglyce } \\
\% \text { Palmitic } \\
\% \text { Linoleic }\end{array}$ & $\begin{array}{l}\mathrm{e} \\
31 \cdot 2(4 \cdot 8) \\
11 \cdot 9(4 \cdot 6)\end{array}$ & $\begin{array}{l}19 \cdot 9(4 \cdot 6) \\
18 \cdot 5(10 \cdot 3)\end{array}$ & $\begin{array}{r}11.3 \text {, SE } 1.33 \\
6.6 \text {, SE } 1.99\end{array}$ & $\begin{array}{l}0.00001 \\
0.0023\end{array}$ \\
\hline $\begin{array}{c}\text { Red-cell memb } \\
\% \text { Palmitic } \\
\% \text { Linoleic }\end{array}$ & $\begin{array}{l}\text { e phosphat } \\
15.9(3.2) \\
13.4(2.3)\end{array}$ & $\begin{array}{l}\text { choline } \\
17 \cdot 8(2 \cdot 8) \\
15 \cdot 2(1 \cdot 6)\end{array}$ & $\begin{array}{l}1.9, \text { SE } 0.75 \\
1.8 \text {, SE } 0.50\end{array}$ & $\begin{array}{l}0.017 \\
0.001\end{array}$ \\
\hline
\end{tabular}

in the patients than in the controls, but the high concentration of palmitic acid in the patients is statistically more impressive. The difference in linoleic acid would occur by chance in two of 1000 trials; the palmitic acid difference is more than 200 times more unexpected.

With regard to the fatty acids in the phosphatidyl choline in the red-cell membrane, Dr Simpson and others convey the impression that the patients and controls differ importantly only in linoleic acid, but, as the table shows, the difference in palmitic acid would occur by chance in only 17 of 1000 trials.

Many rigidly controlled dietary experiments on man agree that the plasma-cholesterol-promoting effect of the saturated fatty acids in the diet is twice as powerful as the opposite effect of an equal amount of linoleic acid. ${ }^{1-3}$ In natural human diets palmitic acid is the dominant saturated fatty acid while linoleic acid is the dominant polyene. Among populations as well as among individuals the variability of the two fatty acids differs greatly. Among 16 population samples of middle-aged men in seven different countries the average contribution of saturated fatty acids to the total calories ranged from 3 to $22 \%$; for polyenes the range varied only from 3 to $5 \%{ }^{4}$

Of course, the variation among individuals is greater, but in most populations the intra-individual variation is so great that it is very difficult to get valid estimates for the average consumption of the different fatty acids for individuals. ${ }^{56}$ For sizable be drawn about a possible role of linoleic acid in the diet as a factor in the aetiology of coronary heart disease.

University of Minnesota School of

ANCEL KeYS

Public

${ }^{1}$ Keys A, Anderson JT, Grande F. Metabolism 1965; $14: 747-87$

gsted DM, McGandy RB, Myers ML, Stare FJ. Am f Clin Nutr 1965;17:281-95.

${ }^{3}$ Keys A, Parlin RW. Am f Clin Nutr 1966;19:175-81. Keys A. Seven countries a multivariate analysis of Mass: Harvard University Press. 1980:1-381

Liù K, Stamler J, Dyer A, et al. $\mathcal{J}$ Chron Dis 1978; 31:399-418.

Jacobs DR, Anderson JT, Blackburn H. Am $\mathcal{f}$

Epidemiol $1979,110: 77-87$ Med 1981;304:65-70.

SIR,-The findings of Dr H C R Simpson and others (11 September, p 683) are in conflict with our findings on the erythrocyte phospholipid linoleic acid content in patients with ischaemic heart disease and in healthy controls. ${ }^{1}$ We measured the erythrocyte phospholipid fatty acids in 15 patients with clinical and electrocardiographic evidence of an acute myocardial infarction. Although the linoleic acid content on average was less in the patients than in the controls, the data were not powerful enough to discriminate between the two groups because of the variations within each group. The reason for this discrepancy between the findings of $\mathrm{Dr}$ Simpson and others and ours is not clear. We made every effort to ensure that the patients had not changed their diet during the preceding few months. It may be that our number was too small to detect a significant difference. We did not measure the fatty acid content of phosphatidyl choline because Farquhar and Ahrens ${ }^{2}$ had reported that there was no change in the properties of the phospholipid classes during four different fat regimens, and they therefore reported the phospholipid fatty acid as a single group. We followed their suggestions. It is important to confirm the conclusions of Dr Simpson and others by a larger study, and also to determine whether Farquhar and Ahren's findings hold for customary (not experimental) diets.

LOUIS A SOLOFF HEINZ SCHWARTZ

Temple University Health Sciences Center,

Philadelphia,

Pennsylvania 19140

${ }^{1}$ Soloff LA, Schwartz H. Lancet 1964 ;ii:1268-9.

Soloff LA, Schwartz H. Lancet $1964 ;$ ii :1268-9.
Farquhar JW, Ahrens EH. $\mathcal{J}$ Clin Invest 1963;42: 675-85.

\section{Breech: vaginal delivery or caesarean} section?

SIR,-The final sentence in Professor J K Russell's leading article (25 September, p 830) states that: "Obstetricians seem steadily to be moving towards a policy of abdominal delivery, but this may well be challenged." I agree. Listed among factors that affect the decision on the mode of delivery is the very important one concerning the experience of the obstetrician. For many years while in clinical charge of a maternity hospital I considered that the obstetric skill of a colleague in training could often best be judged by the smoothness with which a breech delivery was conducted. Few will disagree with the statement that the higher the incidence of elective abdominal delivery the less chance there is for resident staff to gain experience of all the subtle observations and skills associated with the safe management of vaginal breech birth. The acquisition of experience for the specialist in training, however, cannot be considered a factor affecting a clinical decision. I recall over 30 years ago answering an essay question in the examination for membership of the Royal College of Obstetricians and Gynaecologists on the aphorism that the more frequent use of caesarean section was a detriment to the art of obstetrics. I thought then that it was a good question which might be asked in an examination at any level, and this remains applicable today.

That abdominal delivery per se carries an increased risk of maternal and perinatal mortality or morbidity, or both, is undoubted, and this must be given due weight when deciding the mode of delivery. In an endeavour to ascertain the risks to the neonate of the various individual maternal and obstetric factors, a survey was carried out of more than 5000 consecutive deliveries, ${ }^{1}$ and the results indicated that the risk from caesarean section performed for any cause was slightly greater than that associated with vaginal delivery of a 
breech presentation at term. Factors affecting the mode of breech delivery were discussed in a recently published textbook, ${ }^{2}$ as were also the place for induction of labour and that of external cephalic version.

Professor Russell mentions too the important consideration of possible litigation if all does not proceed perfectly. Clinical practices in many disciplines have changed because of the worry of possible litigation, and this, sadly, may not always be to the benefit of the public our profession serves.

Gerald J Amiel

Beckenham,

1 Amiel GJ. Br f Obstet Gynaecol 1960;67:772-84. Amiel GJ. Essential obstetric practice. Lancaster
MTP Press, 1981:108-9.

SIR,-Sometimes I despair of our senior obstetricians. It is surely incredible that Professor Russell should compose a leading article in 1982 on the management of delivery of a breech presentation (25 September, p 830) without including a single reference to anaesthesia or analgesia. It is realistic to assert that the choice-and by extension the availability of choice- of analgesia or anaesthesia for delivery, whether vaginal or abdominal, of a baby presenting by the breech is the most important single determinant of maternal and neonatal well being.

I will not demean your pages by listing the multiplicity of reports in support of this contention-they must be well known to all who hold, or who aspire to hold, membership of the Royal College of Obstetricians and Gynaecologists. Suffice it to say that there is a world of difference between the postnatal course of a series of breech babies delivered vaginally under epidural or spinal block and a similar series delivered without anaesthesia or under pudendal block and that this contrast is even more marked in immature babies. A similar distinction applies to babies delivered by caesarean section. There should, of course, be no disagreement about the relative merits of general anaesthesia and regional analgesia-in the context of adequately staffed obstetric units-regarding maternal well being.

When considering the advisability of vaginal versus abdominal delivery of a breech baby (either singleton or one of a multiple pregnancy) prime consideration must be paid to the availability of anaesthetic expertise. As a generalisation it is, I believe, true to say that a premature breech baby delivered by section under general anaesthetic will be in a worse condition than a premature breech baby delivered vaginally under epidural or spinal block, whereas a similar baby delivered abdominally under continuous epidural block will be in better condition than one delivered vaginally without conduction analgesia.

\section{J SEL WYN CRAwFord} Birmingham Maternity Hospital,
Birmingham B15 2TG

** We sent this letter to Professor Russell, who replies below.-ED, $B M F$.

SIR,-The purpose of my article was to draw attention to the dramatic rise there has been in the caesarean section rate in breech birth in the past decade and to consider some of the implications of this trend. I did mention that one of the reasons for the rise in the section rate is the increasing safety of the operation, but it was not my purpose to single out and examine the part played by specific techniques in anaesthesia and analgesia. Had I done so I suspect that there would rightly have been sharp criticism from colleagues in other disciplines who contribute notably to the successful outcome of breech birth. It is my view that successful breech birth is very much a team effort, and I would hesitate to claim that one member of the team is more important than another.

But let me return to my theme. I do hope that all those involved in the management of breech births will ask with increasing insistence whether the steady trend towards abdominal delivery is justified. I suspect that our patients, in time, will challenge this development in the same way that they have challenged some other developments in modern obstetric practice.

Newcastle upon Tyne NE2 3BD

J K RuSSELL

\section{Are you making the most of "Index} Medicus"?

SIR,-Recently I encountered one of the difficulties in using the Index Medicus mentioned by Jacqueline Welch (16 October, p 1105)-namely, that of finding references relating to a therapeutic technique. I have, however, discovered an alternative reference source, the Science Citation Index, which was much more helpful.

The Science Citation Index consists of three parts:

(1) A citation index, which lists all quoted references in articles in the main science (including the main medical) journals by first-named authors. For each citation indexed it gives the names of each author (first-named for each article) who cited it, the journals or books, volume and page numbers.

(2) A source index, which lists all the articles published in the literature covered by the Index in order of the first-named authors. Co-authors are cross-referenced. The title of the paper, journal, year, and page number are given, with the number of source references and the primary author's address if given with the article.

(3) A permuterm index, which is a system for identifying articles on given subjects. This is achieved by indexing all permutations of all the important words (terms) in pairs from the titles of the articles indexed. It then gives a list of authors, or a journal if an article does not have a named author. The full titles and the rest of the details can then be gathered from the source index.

As an example, I am researching side effects associated with the interscalene brachial plexus block. This was first described by Winnie in $1970 .^{1}$ It was not easy to find relevant articles by using the Index Medicus. But because any paper on interscalene block is very likely to quote Winnie's original paper, I found using the citation index appropriate. Looking under "Winnie AP" and the reference of his original description for each year from 1970 onwards, I soon compiled a comprehensive list of papers quoting him. From these I am gleaning the information I require.

The Science Citation Index should be found in university and major research libraries. It would be too expensive for the average hospital/postgraduate centre library. It is published covering two months at a time through the year, then the Index for the whole year is issued. Indexes covering fiv years have also been produced. Compute searching of this Index is possible for a appropriate fee.

I am drawing attention to the Science Citation Index because it is a research toof which in certain instances is more useful than the Index Medicus, and as such deserves to be better known.

Broadgreen Hospital,
Liverpool L14 3LB

STEPHEN P POR

Winnie AP. Curr Res Anesth Analg 1970;49:455-66.0

Ultrasound measurement of the spind canal in spinal stenosis

SIR,-Dr P Davies (25 September, p 89 has criticised the use of echo ultrasound in the measurement of the lumbar spinal canads While I would support his view that it premature to accept this technique inte routine clinical practice I would disagree with his view that the technique is invalid epidemiological studies.

We have undertaken a preliminary study of the reproducibility of the technique using methods identical to those reported bJ Porter et al. ${ }^{1}$ Duplicate measurements at each lumbar vertebral level were made by one experienced technician on 50 healthy young men. The ultrasound technician had received initial training in the technique from Portet et al followed by five weeks of practice with laboratory personnel as subjects. An initial set of measurements was obtained, and measure ments were then repeated blind in the same test session. The mean age, height, and weight of the subjects were 21.7 years (SD 4.000 $175.9 \mathrm{~cm}$ (SD 6.2), and $69.5 \mathrm{~kg}$ (SD 7.8 ) respectively. None admitted to past or preseng symptoms of back pain or back-related problems.

In contrast to previous reports ${ }^{1}$ of three distinctly separate echoes we found that the first two echoes were seldom clearly separateq and most commonly formed a complex. The mean spinal canal measurement of $1.37 \mathrm{~cm}$ was approximately $0.2 \mathrm{~cm}$ less than previous reported, ${ }^{1}$ but the intersubject variabilit (SD $0.12 \mathrm{~cm}$ ) in the data was similar, suggesting that the difference was systematic rather thas random. The within-session variability was assessed by calculating the modal and mesiag difference and the standard deviation of the differences between the two replicates with each test session using paired data. The moda difference was $0.02 \mathrm{~cm}$. The mean differenge was $0.005 \mathrm{~cm}$. This was not statisticalf significant at the $5 \%$ level. The standare deviation of the difference was $0.051 \mathrm{~cm}$ corresponding to a coefficient of variation $3.7 \%$. Sixty-two per cent of the readin fell within $+0.03 \mathrm{~cm}$

In addition between-session variability hao been investigated (blind) in seven subjects date. The modal between-session difference $0.01 \mathrm{~cm}$. The mean difference is $0.025 \mathrm{~cm}$ (not statistically significant at the $5 \%$ levep The standard deviation of the difference is $0.081 \mathrm{~cm}$, corresponding to a coefficient variation of $5.8 \%$. Forty per cent of thas readings fall within $\pm 0.3 \mathrm{~cm}$.

Our data indicate that the reproducibiliti of the measurement is likely to be adequate for the technique to provide useful data cross-sectional or, preferably, prospectio 